dose of $20 \mathrm{mg} / \mathrm{kg} /$ day (range, $8-39 \mathrm{mg} / \mathrm{kg} /$ day) provided a $>75 \%$ reduction in partial seizures in $84 \%$ patients, and $100 \%$ reduction in $60 \%$. (Report of responses from neurologists provided by Bergman S, Novartis). As add-on therapy in 267 children with partial seizures, a $>75 \%$ reduction in seizure frequency occurred in $27 \%$ vs $7 \%$ in patients receiving placebo. Sixty-one percent of neurologists were already using Trileptal as monotherapy for partial seizures in children ages $4-16$, and $68 \%$ use it as adjunctive therapy. In a review of monotherapy in epilepsy and the role of newer antiepileptic drugs, OXC is as effective as conventional AEDs at controlling partial seizures and is better tolerated (Vasquez B. Arch Neurol Sept 2004;61:1361-1365).

Oxcarbazepine exacerbates myoclonic and absence seizures in juvenile idiopathic generalized epilepsies (IGE), in a report from Montpellier and Marseille, France (Gelisse P et al. Epilepsia 2004;45:1282-1286). Six patients, ages 6 to 19 years, with juvenile IGE were affected; 5 had worsening of myoclonic jerks, 3 had exacerbation of absence seizures (one had absence status); and 3 had a slight increase in generalized tonic clonic seizures.

\title{
RISKS OF ACADEMIC UNDERACHIEVEMENT IN EPILEPSY
}

The relation between neuropsychological functioning and academic achievement and the role of family environment, seizures, and psychosocial variables were examined in 173 children with chronic epilepsy, ages 8 to 15 years, at Purdue School of Science; Indiana University School of Medicine, Indianapolis; and University of Wisconsin-Madison School of Medicine, WI. Verbal/Memory/Executive function and Rapid Naming/Working Memory were strongly correlated with reading, math, and writing ability, whereas Psychomotor function predicted writing ability only. Family environment affected the impact of neuropsychological deficits (NPD) on writing and reading; NPD had a lesser impact on

achievement of children from supportive/organized homes compared to unsupportive/disorganized homes. (Fastenau PS, Shen J, Dunn DW, et al. Neuropsychological predictors of academic underachievement in pediatric epilepsy: moderating roles of demographic, seizure, and psychosocial variables. Epilepsia 2004;45:1261-1272). (Reprints: Dr PS Fastenau, Psychology (LD 124), Indiana University Purdue University Indianapolis, 402 N Blackford St, Indianapolis, IN 46202).

COMMENT. Children with epilepsy who have neuropsychological deficits and live in disorganized unsupportive home environments are particularly at risk for academic underachievement. Aggressive family intervention and counseling to provide more supportive environments might result in improved academic outcome. Involving the family in the learning process is known to benefit learning, and a more organized family life can promote better sleeping habits and full compliance with medication schedules.

Changes in left temporal interictal epileptiform activity during and after cognitive tasks are reported in an 18-year-old male with intractable complex partial seizures (Boniface SJ, et al. J Neurol Neurosurg Psychiatry 1994;57:227-228). (See Ped Neur Briefs April 1994). Activation or suppression of EEG focal spike discharges in relation to psychological testing may have a role in treatment of children with reading and other learning disabilities, and in presurgical assessment of patients with intractable epilepsy. 